\title{
THE DISCLOSURE AND LICENSING OF UNIVERSITY INVENTIONS
}

\author{
Richard Jensen \\ Jerry G. Thursby \\ Marie C. Thursby \\ Working Paper 9734
}


NBER WORKING PAPER SERIES

\title{
THE DISCLOSURE AND LICENSING OF UNIVERSITY INVENTIONS
}

\author{
Richard Jensen \\ Jerry G. Thursby \\ Marie C. Thursby \\ Working Paper 9734 \\ http://www.nber.org/papers/w9734
NATIONAL BUREAU OF ECONOMIC RESEARCH 1050 Massachusetts Avenue
Cambridge, MA 02138 \\ May 2003
}

We thank John Scott, two anonymous referees, and participants of the Workshop on the Economics of Intellectual Property at Universities sponsored by the University of North Carolina at Greensboro and Rensselaer Polytechnic Institute for comments. We gratefully acknowledge support from the Sloan Foundation and the National Bureau of Economic Research under the NBER Project on Industrial Technology and Productivity. J. and M. Thursby thank the Alan and Mildred Peterson Foundation for support through the Purdue Technology Transfer Initiative and the National Science Foundation (SES- 0094573). M.Thursby acknowledges support from NSF-IGERT 022160. Special thanks go to members of the Association of University Technology Managers who talked to us in the process of designing the survey. The views expressed herein are those of the authors and not necessarily those of the National Bureau of Economic Research.

C2003 by Richard Jensen, Jerry Thursby, and Marie Thursby. All rights reserved. Short sections of text not to exceed two paragraphs, may be quoted without explicit permission provided that full credit including (C) notice, is given to the source. 
The Disclosure and Licensing of University Inventions

Richard Jensen, Jerry Thursby, and Marie Thursby

NBER Working Paper No. 9734

May 2003

JEL No. O31, O32, L31

\section{$\underline{\text { ABSTRACT }}$}

We examine the interplay of the three major university actors in technology transfer from universities to industry: the faculty, the technology transfer office (TTO), and the central administration. We model the faculty as an agent of the administration, and the TTO as an agent of both the faculty and the administration. Empirical tests of the theory are based on evidence from our survey of 62 US research universities. We find that the TTOs reported licensing objectives are influenced by their views of faculty and administration, which supports the assumption that the TTO is a dual agent. The theory yields predictions for whether or not faculty disclose inventions and if so, at what stage, which in turn affects license contract terms. We also examine how the portion of inventions disclosed at different stages varies with faculty quality. Quality is found to be inversely related to the share of license income allotted to faculty.

Richard A. Jensen University of Notre Dame rjensen1@nd.edu
Jerry G. Thursby Emory University jthursb@emory.edu
Marie C. Thursby DuPree College of Management Georgia Institute of Technology 755 Ferst Drive Atlanta, GA 30332-0520 and NBER marie.thursby@mgt.gatech.edu 


\section{Introduction}

In the more than two decades since the Bayh-Dole Act gave universities the right to own and license inventions from federally funded research, the number of technology transfer offices (TTOs) in U.S. universities has grown from 25 to well over 200. These are the offices with primary responsibility for implementation of the Bayh-Dole Act. While TTO objectives and organization vary across universities (see Bercovitz et al. (2001), Siegel et al. (1999), and Thursby et al. (2001)), all TTOs are charged with facilitating and managing the disclosure and licensing of inventions with commercial potential. In carrying out this mission, the TTO must balance the objectives of the university, which owns the inventions, and the faculty, who create them. ${ }^{1}$

In this paper, we present and test a model that allows us to examine this balancing act and its effect on a critical element in the transfer processthat is, whether or not inventions are disclosed by faculty, and if so, when. In our recent survey of the TTOs of 62 U.S. universities, TTO directors reported that educating and convincing faculty to disclose inventions is one of their major problems. ${ }^{2}$ Many directors believe that substantially less than half of the inventions with commercial potential are disclosed to their office. Faculty may not disclose for a variety of reasons ranging from not being able to realize an invention has commercial potential to not wanting to take time away from their research. Many faculty may not want to get involved in licensing because, as reported in the survey, faculty involvement in further development (even after a license is executed) is necessary for commercial success for $71 \%$ of the inventions licensed.

Not surprisingly, the directors we talked with believe that some of the best inventions may not be disclosed because the most productive faculty are less likely to want to take the time to disclose inventions, much less work on further development. Paradoxically, the directors we talked with also believe that many of the inventions disclosed to them are of questionable value. Indeed, the director of a major university TTO described the TTO's job as "the best we can do with the $\mathrm{s}^{* *} \mathrm{t}$ we get to work with." This suggests that the nature of inventions disclosed in U.S. universities is related to faculty quality, and perhaps, in ways that are unexpected. While one might expect higher quality faculty to produce higher quality inventions, and on average

\footnotetext{
${ }^{1}$ Thursby et al. (2001) report that, even for industry funded inventions, less than $5 \%$ of the universities in the survey allow faculty ownership of inventions.

${ }^{2}$ As noted in Appendix A, questionnaires were sent to 135 universities for a 46 percent response rate.
} 
they very likely do, it may well be the case that a significant fraction of these inventions are not disclosed to the TTO. Indeed, if high quality faculty can obtain research funding without producing research with commercial potential, or are simply more interested in publication of their research, then one can argue that the fraction of inventions disclosed would be decreasing in the quality of faculty inventors.

Given the importance of disclosure to the university technology transfer process, we construct and analyze a game-theoretic model of this process in which the central administration is the principal and both the TTO and faculty are agents, but the need for disclosure implies the TTO is also an agent for the faculty. The administration affects TTO and faculty incentives by setting the shares of license income and sponsored research they each receive. The inventor's choice is whether to disclose, and if so, whether to disclose the invention as soon as it is a proof of concept or to wait until it is a lab-scale prototype. For inventions disclosed, the TTO chooses whether or not to search for a licensee and determines the royalty income and sponsored research in licenses executed. The administration, TTO, and inventor are all expected utility maximizers, and we allow their utility to depend on whether a license is executed, as well as license income and sponsored research. Quality enters the model through its positive effect on the probability that an invention is commercially successful.

The analysis yields predictions for contract terms as well as the stage of development of inventions disclosed. In equilibrium, license income and sponsored research are a function of quality, the licensee's cost of commercialization, profit from successful commercialization, and the share of returns that accrue to the TTO. Because of the effect of quality on the probability of success, the TTO may include sponsored research in a license even if she receives a zero share of these funds. In equilibrium, whether the inventor discloses, and at what stage, is a function of the equilibrium license income and sponsored research, the inventor's rate of time preference, and quality. While, in general, comparative static results are ambiguous, we present plausible conditions under which higher quality faculty would disclose a higher fraction of inventions at the proof of concept stage.

Empirical tests of the model provide support for the dual agency view that TTOs measure their own success based on their perceptions of both faculty and central administration objectives. Moreover, the more important the TTO thinks an objective is to the two principals, the more she pays attention to that objective as a measure of success. For example, our survey results show that the TTO does not place as much weight on sponsored research as a license outcome as do faculty inventors or the central 
administration. Only 34 percent of TTOs thought it was extremely important, while 48 percent of central administrations and 75 percent of inventors did. Nevertheless, our econometric results show that faculty and central administration are a significant determinant of a TTO's view of sponsored research, and that the TTO is more responsive to the faculty's view of sponsored research. Furthermore, 71 percent of TTOs and 69 percent of central administrations thought royalties were extremely important, but only 41 percent of inventors did. In this case our econometric results suggest that the TTO pays more attention to the administration's view.

With respect to the stage of development, we find that universities with higher academic rankings for their faculty have a higher proportion of disclosures licensed in the proof of concept stage. In the context of our theory, this supports the view that the marginal impact of quality on the probability of success is highest at the proof of concept stage. We also find that universities with higher fractions of inventions from medicine and nursing or from engineering have a higher proportion of disclosures licensed in the proof of concept stage. Although this might appear to be counterintuitive for engineering, an applied science, this might simply be an indication of a difference in attitudes towards commercialization. That is, engineering faculty may be more willing to participate in licensing, and thus more willing to disclose early. ${ }^{3}$ In addition, it may well be the case that early stage inventions in engineering have, in general, more obvious commercial potential because the research in engineering, as in medicine and nursing, tends to be more applied. Interestingly, we also find that universities with greater net income have a smaller proportion of disclosures licensed in the proof of concept stage. We believe this follows from "wealthier" TTOs discouraging early stage inventions. However, as expected, more successful TTOs with greater income per license encourage disclosure at the proof of concept stage.

Finally, consistent with our assumption that administrations maximize expected utility subject to participation constraints for the TTOs and inventors, we find that the share of royalty income allotted to inventors is lower for universities with higher quality faculty.

These results contribute to the burgeoning literature on university-industry technology transfer, which has tended to abstract from examining the role of the TTO in the process. Notable exceptions include Bercovitz et al. (2001) and Siegel et al. (1999), who take an organizational perspective, and Hoppe and Ozdenoren (2001), who focus on the TTO as an intermediary signal-

\footnotetext{
${ }^{3}$ See Louis et al (2001) and Owen-Smith and Powell (2001) for discussions of different perceptions across fields regarding technology transfer.
} 
ing the quality of inventions to potential licensees. Thursby et al. (2001), Thursby and Thursby (2001), and Jensen and Thursby (2001) discuss the role of TTOs in structuring license contracts to induce inventor cooperation in further development after license execution. While they acknowledge the balancing act played by the TTO, they abstract from the critical issue of inducing faculty to disclose inventions. Finally, little work has been done of the role of faculty quality in the process. In this regard, notable exceptions are Thursby, Jensen, and Thursby (2001), Thursby and Kemp (2002), DeGregorio and Shane (2000), and Lach and Shankerman (2002).

\section{A Theoretical Model of Disclosure and Licens- ing}

We choose to model the university licensing process as a game in which the central administration of the university, $A$, is the principal, and both the technology transfer office (TTO), $T$, and the faculty inventor, $I$, are agents. Essentially, the administration selects contract terms for both the TTO and inventor, who then play a sequential move game of disclosure and licensing. The basic unit of observation is a particular research project by the inventor that yields a potential invention at the "proof of concept" stage of development. As shown in Figure 1, at this stage the inventor has three choices. He can: disclose this potential invention to the TTO; continue research to develop the potential invention to the "lab-scale prototype" stage; or switch to another project. ${ }^{4}$ If he discloses, then the TTO can either search for a potential partner/licensee or shelve the disclosure (i.e., return it to the inventor). If he continues research, then when the potential invention is developed to the lab-scale prototype stage his choices are to disclose it to the TTO or switch to another project. If he discloses, the TTO's choices are to search for a partner or return the disclosure to the inventor. Note that, although the additional research required to further develop the potential invention involves a time cost and an effort cost, it also increases the probability of commercial success, and thus the probability the TTO can find a partner and sell a license. Finally, when the inventor switches to another

\footnotetext{
${ }^{4}$ We abstract from a fourth possibility-that the inventor could attempt to commercialize the invention herself rather than disclose it. Because universities are quite willing to protect their property rights to faculty inventions, this choice would only be relevant if she is willing to risk the inevitable legal consequences, as might be the case if the invention has a high enough market value, or if she preceives the likelihood that the university can successfully enforce its property rights is very low.
} 
project, he earns the (reservation) utility associated with it.

\subsection{The TTO's Problem}

To solve this by backward induction, first consider the subgames between the TTO and the potential licensee. We consider contracts of the form $(R, S)$, where $R$ is the present discounted value of the stream of license revenue paid by the firm, and $S$ denotes funds provided to the university for sponsored research. Sponsored research is paid at the time the license agreement is signed, while royalties, which represent the bulk of license revenue, are not paid unless and until the invention is successfully commercialized. ${ }^{5}$ The firm undoubtedly also bears some costs associated with adopting and/or marketing the invention, which we denote by $K$. Let $\Pi$ be the present discounted value of the stream of profits resulting from the invention if it is a commercial success. If $p$ is the probability of success at the time the TTO searches for a partner, then she can sell a license only if $p(\Pi-R)-S \geq K$. With this formulation, we ignore all up-front license payments except those for sponsored research, and we abstract from any output effects of royalties, focusing instead on the critical role of the probability of success. ${ }^{6}$ Note that the TTO cannot even give a license away, $R=S=0$, unless the probability of commercial success is high enough, $p \geq \frac{K}{\Pi}$.

There are two probability of success functions, depending on the stage of development at the time of disclosure. If the invention is disclosed as a proof of concept, then the probability of success is $p_{C}(S, Q)$, where $Q$ is an index of faculty quality. Several studies show the importance of faculty involvement in further development if university inventions are to be successful commercially (Agrawal and Henderson 2002, Jensen and Thursby 2001, Thursby and Thursby 2002). Here we assume that sponsored research and faculty quality both improve the probability that this effort will be successful, so that $p_{C}(S, Q)$ is increasing at a decreasing rate in both arguments, and is strictly concave. Similarly, if the invention is disclosed as a lab-scale prototype, then the probability of success is $p_{L}(S, Q)$, which we also assume is increasing at a decreasing rate in both arguments and is strictly concave. We further assume that $0<p_{C}(S, Q)<p_{L}(S, Q)<1$, so there is some positive probability of success, even without further development, but success is never a sure thing, and the probability of success, ceteris paribus, is always

\footnotetext{
${ }^{5}$ See Jensen and Thursby (2001) and Thursby, Jensen, and Thursby (2000) for the prevalence of royalty contracts.

${ }^{6}$ See Jensen and Thursby (2001) for an analysis of the inefficiency of royalty as compared to equity contracts.
} 
greater for an invention at the lab-scale prototype stage than at the proof of concept stage.

We assume that the TTO director maximizes expected utility. Her utility is $U_{T}\left(y_{T}, f_{T}, \ell\right)$, where $y_{T}$ is her license income, $f_{T}$ is her sponsored research funds, and $\ell$ is an indicator variable with $\ell=1$ if a license is executed and $\ell=0$ if not. As is standard among TTOs in the U.S., sponsored research associated with a license is not considered as license income. Funds for sponsored research are typically explicitly linked to continued development by the inventor, and she may or may not be entitled to a share of those funds. Moreover, as noted earlier, these funds are paid up-front, at the time of licensing, while the bulk of license income comes from royalties which are paid only if the invention succeeds. Naturally we assume positive but diminishing marginal utility from license income and sponsored research, and positive marginal utility from execution of a license. Without loss of generality, we assume $U_{T}(0,0,0)=0$. We also assume that her share of license income, $\alpha_{R}$, need not be the same as her share of sponsored research funds, $\alpha_{S}$ (indeed, for many respondents, $\alpha_{S}=0$ ). Because the Bayh-Dole Act specifically encourages universities to collaborate with commercial concerns to promote the utilization of inventions arising from federal funding, and TTOs are charged with this mission, she gets utility simply from executing a license, $U_{T}(0,0,1)>0$. Finally, her utility cost of searching for a licensee is $V_{T \ell}>0$, so that searching is not optimal at any stage unless it generates, in expectation, sufficient additional utility (otherwise she shelves the potential invention). Her expected utility from executing a license contract $(R, S)$ at stage $j=C, L$ is thus

$$
\begin{aligned}
E U_{T j}\left(\alpha_{R} R, \alpha_{S} S\right)= & p_{j}(S, Q) U_{T}\left(\alpha_{R} R, \alpha_{S} S, 1\right)+ \\
& {\left[1-p_{j}(S, Q)\right] U_{T}\left(0, \alpha_{S} S, 1\right)-V_{T \ell} . }
\end{aligned}
$$

Consider the contracting problem at stage $j=C, L$, assuming that the TTO director has decided to search for a licensee. A firm accepts a contract $(R, S)$ only if its expected profit under that contract is nonnegative, where its expected profit at stage $j=C, L$ is

$$
E \Pi_{j}(R, S)=p_{j}(S, Q)(\Pi-R)-S-K .
$$

The TTO director's problem at stage $j$ is to choose a contract $(R, S)$ that maximizes her expected utility subject to the licensee's participation (nonnegative expected profit) constraint,

$$
\max _{R \geq 0, S \geq 0} E U_{T j}\left(\alpha_{R} R, \alpha_{S} S\right) \text { s.t. } E \Pi_{j}(R, S) \geq 0 .
$$


We denote the solution values for this problem by $\left(R_{j}^{*}, S_{j}^{*}\right)$. The solution is $\left(R_{j}^{*}, S_{j}^{*}\right)=(0,0)$ when expected profit is negative even if the license is given to the firm at no cost, or $E \Pi_{j}(R, S)<0$ for all $R \geq 0$ and $S \geq 0$. However, note that $p_{j}(0, Q)>\frac{K}{\Pi}$ is a sufficient to guarantee $E \Pi_{j}(R, S)>0$ for some $R>0$ and $S>0$, and thus that the solution to (3) has $R_{j}^{*}>0, S_{j}^{*}>0$, or both.

Because the TTO director gets utility from simply executing a license contract, it is possible that she would search for a licensee even if it resulted in no license income or sponsored research funds for her, $E U_{T j}(0,0)=$ $U_{T}(0,0,1)-V_{T \ell}>0$. However, in general, she does not search for a licensee unless her expected utility from her share of the contract is nonnegative,

$$
E U_{T j}\left(\alpha_{R} R_{j}^{*}, \alpha_{S} S_{j}^{*}\right) \geq 0 .
$$

The solution to this licensing problem and the comparative statics results for an interior solution are of interest.

Theorem 1 If $p_{j}(0, Q)>\frac{K}{\Pi}$, then at the solution $\left(R_{j}^{*}, S_{j}^{*}\right)$ to $(3)$, a licensee's participation constraint is binding, $E \Pi_{j}\left(R_{j}^{*}, S_{j}^{*}\right)=0$, and either $R_{j}^{*}>0, S_{j}^{*}>0$, or both. The participation constraint is also negatively sloped at the maximum, whether it is interior or not. If, in addition, the TTO director's participation constraint (4) holds at $\left(R_{j}^{*}, S_{j}^{*}\right)$, then she searches for a licensee and executes the contract. If the solution is interior, then:

(i) An increase in either share $\alpha_{R}$ or $\alpha_{S}$ must either increase $R_{j}^{*}$ and decrease $S_{j}^{*}$, decrease $R_{j}^{*}$ and increase $S_{j}^{*}$, or leave them unchanged.

(ii) An increase in quality $Q$ or profit from a success $\Pi$ and a decrease in the cost of commercialization $K$ must increase either $R_{j}^{*}$ or $S_{j}^{*}$, or both.

These results follow directly from the participation constraints of the firm and TTO director. If $p_{j}(0, Q)>\frac{K}{\Pi}$, then expected profit at $(R, S)=(0,0)$ is strictly positive, so a licensee can be found and a contract $\left(R_{j}^{*}, S_{j}^{*}\right)$ with $R_{j}^{*}>$ $0, S_{j}^{*}>0$, or both can be executed. She will incur the disutility of searching for the licensee to execute the license contract if $E U_{T j}\left(\alpha_{R} R_{j}^{*}, \alpha_{S} S_{j}^{*}\right) \geq 0$. Moreover, because $E U_{T j}\left(\alpha_{R} R, \alpha_{S} S\right)$ is increasing in $R$ and $S$, but $E \Pi_{j}(R, S)$ is decreasing in $R$ and $S$, the optimal contract must have the licensee's participation constraint binding at the maximum, $E \Pi_{j}\left(R_{j}^{*}, S_{j}^{*}\right)=0$. And because her indifference curves (in expected utility) are negatively sloped, this constraint must be downward sloping at the maximum, whether it is interior or at either corner. Thus, parametric changes such as changes in $Q$, $\Pi$, and $K$ that increase $E \Pi_{j}(R, S)$ result in an outward shift of the constraint 
from the point $\left(R_{j}^{*}, S_{j}^{*}\right)$, so either $R_{j}^{*}$,or $S_{j}^{*}$, or both, must increase at the new maximum on the new constraint. While changes in her shares affect the TTO director's expected utility, they do not shift the firm's participation constraint, so that either $R_{j}^{*}$ and $S_{j}^{*}$ remain unchanged, or one must decrease if the other increases. Which of these occurs depends on the effect of the shares on the TTO director's marginal rate of substitution of royalties for sponsored research funds. For example, as we show in the appendix, if TTO utility is additively separable, then an increase in her share of license revenue increases $S_{j}^{*}$ and decreases $R_{j}^{*}$, while increase in her share of sponsored research funds increases $R_{j}^{*}$ and decreases $S_{j}^{*}$.

Theorem 2 Assume the TTO director does not receive a share of sponsored research funds, $\alpha_{S}=0$. If $p_{j}(0, Q)>\frac{K}{\Pi}$ and $\frac{\partial p_{j}(0, Q)}{\partial S} \geq \frac{1}{\Pi-R_{j}^{0}}$, where $R_{j}^{0}$ is defined by $E \Pi_{j}\left(R_{j}^{0}, 0\right)=0$, then the solution to (3) necessarily has $S_{j}^{*}>0$.

Again suppose $p_{j}(0, Q)>\frac{K}{\Pi}$, so a licensee can be found if the TTO searches. The contract $\left(R_{j}^{0}, 0\right)$ is the one that chooses the maximum license revenue consistent with non-negative expected profit. This contract cannot be optimal if the marginal impact of the first dollar in sponsored research

funds received on the probability of success is large enough, $\frac{\partial p_{C}(0, Q)}{\partial S} \geq$ $\frac{1}{\left(\Pi-R_{j}^{0}\right)}$. Thus, the TTO may execute a contract that contains sponsored research, even if she receives none of these funds. The reason is that she recognizes that these funds can assist the inventor in the continued effort to develop the invention for commercialization in a way that substantially enhances the probability of success, and hence her expected utility from license revenue.

\subsection{The Inventor's Problem}

We assume that the inventor is an expected utility maximizer with utility function from disclosing an invention $U_{I}\left(y_{I}, f_{I}, \ell\right)$, where $y_{I}$ is his license income, $f_{I}$ is his sponsored research funds. Again, we treat license income differently from sponsored research funds, and we also assume that the inventor's share of license income, $\beta_{R}$, need not be the same as his share of sponsored research funds, $\beta_{S}$. The inventor's utility cost of disclosure is $V_{I d}>0$, so his expected utility from disclosing an invention at the lab-scale prototype stage for which the TTO can find a licensee at the contract $(R, S)$ is

$$
\begin{aligned}
E U_{I L}\left(\beta_{R} R, \beta_{S} S\right)= & p_{L}(S, Q) U_{I}\left(\beta_{R} R, \beta_{S} S, 1\right)+ \\
& {\left[1-p_{L}(S, Q)\right] U_{I}\left(0, \beta_{S} S, 1\right)-V_{I d} }
\end{aligned}
$$


If the inventor does not disclose, he receives the utility from his next best alternative research project, $U_{I a}>0$. Thus, he discloses this stage only if

$$
E U_{I L}\left(\beta_{R} R_{L}^{*}, \beta_{S} S_{L}^{*}\right) \geq U_{I a}
$$

and otherwise he automatically turns to the next best research project.

At the proof of concept stage, his decision is more complex. If he discloses at that stage, his expected utility is

$$
\begin{aligned}
E U_{I C}\left(\beta_{R} R, \beta_{S} S\right)= & p_{C}(S, Q) U_{I}\left(\beta_{R} R, \beta_{S} S, 1\right) \\
& {\left[1-p_{C}(S, Q)\right] U_{I}\left(0, \beta_{S} S, 1\right)-V_{I d} . }
\end{aligned}
$$

If he continues to the prototype stage, his expected utility discounted back to the proof of concept stage is $\delta \max \left\{E U_{I L}\left(\beta_{R} R_{L}^{*}, \beta_{S} S_{L}^{*}\right), U_{I a}\right\}$, where $\delta \in$ $(0,1)$ is his discount factor. Thus, he discloses at the proof of concept stage only if

$$
E U_{I C}\left(\beta_{R} R_{C}^{*}, \beta_{S} S_{C}^{*}\right) \geq \max \left\{\delta\left[E U_{I L}\left(\beta_{R} R_{L}^{*}, \beta_{S} S_{L}^{*}\right)\right], U_{I a}\right\} .
$$

This plus the results in Theorem 1 immediately lead to the following.

Theorem 3 The subgame perfect equilibria of the game between the inventor and TTO director can be characterized as follows:

(i) If $p_{C}(0, Q)>\frac{K}{\Pi}, E U_{T C}\left(\alpha_{R} R_{C}^{*}, \alpha_{S} S_{C}^{*}\right) \geq 0$, and $E U_{I C}\left(\beta_{R} R_{C}^{*}, \beta_{S} S_{C}^{*}\right) \geq$ $\max \left\{\delta\left[E U_{I L}\left(\beta_{R} R_{L}^{*}, \beta_{S} S_{L}^{*}\right)\right], U_{I a}\right\}$, then the inventor discloses at the proof of concept stage and the TTO director searches for a licensee and executes a license contract.

(ii) If $p_{L}(0, Q)>\frac{K}{\Pi}, E U_{T L}\left(\alpha_{R} R_{L}^{*}, \alpha_{S} S_{L}^{*}\right) \geq 0$, and $\delta E U_{I L}\left(\beta_{R} R_{L}^{*}, \beta_{S} S_{L}^{*}\right) \geq$ $\max \left\{E U_{I C}\left(\beta_{R} R_{C}^{*}, \beta_{S} S_{C}^{*}\right), U_{I a}\right\}$, then the inventor discloses at the lab-scale prototype stage and the TTO director searches for a licensee and executes a license contract.

(iii) Otherwise, the inventor immediately switches to his best alternative research project and does not disclose the invention.

The higher is the inventor's utility from alternative research or his discount rate (i.e., the lower is $\delta$ ), the more likely it is that he will disclose an invention at the proof of concept stage, if at all. However, higher faculty quality, license income, or sponsored research increase expected utility in both stages, and so have ambiguous effects on the stage of disclosure. Notice that even if $p_{j}(0, Q)>\frac{K}{\Pi}$ and $E U_{T j}\left(\alpha_{R} R_{j}^{*}, \alpha_{S} S_{j}^{*}\right) \geq 0$ for $j=C, L$, so that the inventor knows the TTO is willing and able to execute a license, he may not disclose. He will not disclose at all if the utility from 
his next best alternative, which includes the value of immediate publication of the results, outweighs the expected utility of disclosure at either stage, $U_{I a}>\max \left\{\delta\left[E U_{I L}\left(\beta_{R} R_{L}^{*}, \beta_{S} S_{L}^{*}\right)\right], E U_{I C}\left(\beta_{R} R_{C}^{*}, \beta_{S} S_{C}^{*}\right)\right\}$.

An important implication of this result is that, while the inventor and TTO are both agents of the administration, in the subgame between the inventor and TTO, the TTO is an agent of the inventor. Given the inventor's rate of time preference and the shares set by the administration, his expected utility in each stage is determined by the terms of the contract executed by the TTO. Unless the TTO executes a license that is sufficiently attractive to the inventor, he will never disclose an invention to her, but instead simply publish his research and move on to his next research project, in which case the TTO has nothing to license. Our model therefore implies that the TTO is a "dual" agent whose actions are influenced by the decisions of the administration and the inventors, a relationship that we test in Section 3.

\subsection{The Administration's Problem}

The administration selects the contract terms for both the TTO and inventor, which in this model is represented by the shares of license income and sponsored research that the TTO and inventor receive. From our survey, it is clear that these shares are set as a part of overall university policy on intellectual property and are rarely changed. ${ }^{7}$ We shall therefore take them as given and abstract from the details of the administration's problem. However, we do assume that the administration's utility also depends on license income, sponsored research funds, and whether a license is executed. We also assume it maximizes expected utility, subject to the participation constraints of the TTO and inventor. Therefore, because it receives license revenue $\left(1-\alpha_{R}-\beta_{R}\right) R_{j}^{*}$ and sponsored research funds $\left(1-\alpha_{R}-\beta_{R}\right) S_{j}^{*}$ from a successful license executed at stage $j$, its expected utility is strictly decreasing in the shares of license revenue and sponsored research funds paid to the TTO and inventor.

Because the shares do not vary by stage of development or invention, either the TTO or the inventor, or both, are likely to earn rents on some inventions. For example, if $R$ and $S$ are "normal" goods with respect to TTO's expected utility, then license revenue and sponsored research funds should both be greater if the contract is executed at the lab-scale prototype

\footnotetext{
${ }^{7}$ For many universities in the sample, income shares were set by their Board of Trustees as early as the 1970s. Notable exceptions include the University of California system, which altered the shares in the 1990s when the system was changed from one centralized office to a combination of a central office and campus offices.
} 
stage, where the probability of success is higher, or $R_{L}^{*}>R_{C}^{*}$ and $S_{L}^{*}>S_{C}^{*}$. Thus, if the administration sets the shares so that the TTO's participation binds for inventions disclosed at the lab-scale prototype stage, then she has no incentive to try to license an invention disclosed at the proof of concept stage, and so the inventor would not disclose an invention at that stage. Alternatively, if the administration sets the shares so that her participation constraint binds for inventions disclosed at the proof of concept stage, then she earns rents on inventions disclosed at the lab-scale prototype stage.

Finally, it is interesting to note that we can obtain some testable implications about the administration's choice of the inventor's shares simply by examining his participation constraint. Recall that an increase in quality increases a licensee's expected profit, and thus the license revenue and sponsored research funds in a contract executed at either stage, $R_{j}^{*}$ and $S_{j}^{*}$. An increase in quality therefore increases the inventor's expected utility for given shares $\beta_{R}$ or $\beta_{S}$, and thus relaxes both of his participation constraints. Because the license revenue and sponsored research funds contracted by the TTO do not depend on the inventor's shares, an increase in quality allows the administration to reduce the inventor's shares (and thereby increase its own shares) without violating his participation constraints. An increase in the value of a successful invention $\Pi$ similarly allows an increase in the administration's shares at the expense of the inventor.

\section{Empirical Tests of the Dual Agency Model}

We have modeled university disclosure and licensing as a dual agency problem in which the TTO is an agent for both the administration and inventor. This modeling choice seemed appropriate for several reasons. One is the obvious point that while the university owns all intellectual property resulting from patentable research, it is the TTOs that are central to the operation of university-industry technology transfer. The more subtle point comes from our conversations with TTO directors in the process of designing our survey. These directors uniformly expressed the view that their job was to do the best they could in terms of implementing Bayh-Dole, given the constraints placed on them by their administration and the nature of inventions disclosed by their faculty (i.e., "the best we can do with the $\mathrm{s}^{* *} \mathrm{t}$ we get to work with"). The model presented in Section 2 formalizes this relationship, allowing us to examine the implications for TTO behavior in terms of license objectives, licenses executed, the stage of development at which inventions are disclosed, as well as the effects of faculty quality on the process. 
In this section, we test the model's implication that a TTO's objectives in executing a license must take into account the interests of their two principals, the administration and faculty. To test this hypothesis, we exploit survey evidence on TTO views of the importance of different contract terms and outcomes, from their own perspective, as well as their perceptions of the importance of contract terms to their administration and faculty. We asked respondents to indicate the importance to them of a set of objectives by answering the question, "How important to you are the following measures of success?". In our model, we focused on the three measures of success or "objectives" that were the most important to respondents, that is: (1) royalties/license fees generated, (2) sponsored research funds, and (3) number of licenses/options signed. For each measure, the TTO could indicate "Not very important," "Moderately important" or "Extremely important." Respondents were also given an opportunity to indicate that an outcome was "Not applicable." 8 We also asked respondents about their perceptions of the importance the faculty and administration attach to these objectives. We asked "In your experience, how important do the following measures of success seem to be to the faculty you have worked with?," and "In your experience, how important do each of the following seem to be to your administration?" Each question was followed by the objectives noted above. It is important to note that in asking these questions, our goal was not to determine the actual importance that the administration and faculty attach to these objectives, but rather to characterize TTO perceptions of their importance. $^{9}$ This allows us to examine empirically the probability that the TTO will consider an objective important as a function of the perceived importance to her administration and faculty. In Section 3.1 we present an econometric model that allows us to make such inferences.

\subsection{Econometric Model}

We consider the importance the TTO of university $i(i=1, \ldots, n)$ assigns to objective $j(j=1, \ldots 3), I M P O R T_{i}^{j}$, to be determined by a set of observable characteristics and a random, unobservable disturbance. We do not observe $I M P O R T_{i}^{j}$, instead we observe the categorical values the TTO is willing to assign to the importance of each objective. For ease of estimation, and without loss of generality, we assign the numerical scores $T T O_{i}^{j}=1,2$

\footnotetext{
8 "Not applicable" responses are dropped from the econometric analysis.

${ }^{9}$ Hence our purpose is quite different from the industrial psychology literature which examines agreement among workers and supervisors concerning perceptions of each other's performance (see, for example, Atwater et al. (1998)).
} 
and 3 to the categories "Not very important," "Moderately important" and "Extremely important," respectively. The method of estimation is ordered probit for all objectives except for royalties. Only one TTO responded that royalties were not very important hence inclusion of that valuation as a separate class would not be statistically meaningful. For royalties we use a bivariate probit model to differentiate "extremely important" from other valuations.

The determinants of IMPORT ${ }_{i}^{j}$ are measures of the TTO's perceptions of the importance their faculty and administration attach to objective $j$, the types of inventions produced by the faculty, characteristics of the university and the experience and orientation of the TTO.

$F A C_{i}^{j}$ and $A D M I N_{i}^{j}$ are the ordinal valuations the TTO at university $i$ believes their faculty and administration have for objective $j$. For each of $F A C_{i}^{j}$ and $A D M I N_{i}^{j}$ we assign the same values 1,2 or 3 as we did for the TTO. ${ }^{10}$ Positive coefficients on $F A C_{i}^{j}$ and $A D M I N_{i}^{j}$ would support our view that the disclosure and licensing problem is one of dual agency, with negative or insignificant coefficients rejecting the model.

We expect the importance the TTO assigns to different measures of success to also be a function of the nature of inventions disclosed to her. For example, it is difficult to specify royalty income based on sales (i.e., running royalties) for very early stage technologies since the nature of the final product is often unknown, and it is difficult to define a royalty schedule for a good whose final nature is diffuse. If a large proportion of the disclosures to the TTO are early stage inventions, it is conceivable that she will, all else equal, consider royalties as less important in determining her success than will a TTO with primarily late stage disclosures. Ideally, we would include as measures of the nature of inventions the stage of development of disclosures to the TTO. Unfortunately, we do not have information on stage of development for all disclosures. In our survey we asked the percentage of licensed disclosures that were in various stages of development at the time a license was negotiated: "What percentage of the invention disclosures which have been licensed in the last five years were in the following stages of development at the time the license was negotiated?" As regressors, we use the percentage of licenses that were only "Proof of concept but no prototype" $\left(P R O O F_{i}\right)$ and the percentage where there was a "Prototype available but only lab scale (further development needed)" ( $\left.P T Y P E_{i}\right)$. An invention in

\footnotetext{
${ }^{10} \mathrm{An}$ alternative would be to form a set of indicator variables. However, since the dependent variable consists of the same set of ordinal measures ("not very important," etc.) we feel it more appropriate to measure faculty and central administration importance via the ordinal rankings.
} 
either state $P R O O F_{i}$ or $P T Y P E_{i}$ is considered to be in an early stage of development and $P R O O F_{i}$ is earlier than $P T Y P E_{i}$ We experimented with using the sum of these two measures rather than introducing them separately, but the results were not as revealing.

We include a measure of faculty quality, $Q U A L_{i}$, because as we assume in our theoretical model, we expect quality to affect the probability that inventions will be commercially successful, and hence the stage at which inventions are disclosed and the equilibrium contract terms. For our measure of quality we use the 1993 National Research Council's (NRC 1995) survey results regarding the academic quality of Ph.D. granting departments. This measure is flawed since it considers only the quality of $\mathrm{Ph} . \mathrm{D}$. granting departments. However, apart from medical schools, it is plausible that substantial research programs have difficulty existing in the sciences and engineering without Ph.D. students. We use a weighted average of the department quality scores where the weights are faculty size. The quality scores range from 0 to 5 where 5 indicates a distinguished department.

Thursby and Kemp (2002) and Thursby and Thursby (2002) present evidence that university licensing outcomes and efficiencies are influenced by the presence of a medical school. Whether this presence influences outcomes via different preferences of medical school faculty versus other faculty or via generally different characteristics of medical school inventions versus other inventions is not clear. In addition, our measure of quality does not include medical school faculty except in those cases where a faculty member has an appointment in a Ph.D. granting department. Hence we also include an indicator variable for the presence or absence of a medical school ( $M E D S C H L_{i}$ $=1$ if there is a medical school, 0 otherwise) .

We also include the ratio of industry research support to federal research support $\left(I N D F E D_{i}\right)$. Greater industry support relative to federal support can suggest a greater applied rather than basic research orientation of the faculty. Further, the Bayh-Dole Act of 1980, which grants to universities rights of ownership of innovations developed with federal research support, requires that commercializable inventions be disclosed to the university's TTO and that universities retain ownership of those innovations. Universities with large federal research support are expected to consider compliance with Bayh-Dole as an important measure of their success. We use the averages of industry and federal support over 1992-97.

We consider a single measure of general university characteristics. We include whether a university is public or private $\left(P U B L I C_{i}=1\right.$ if university $i$ is public, 0 otherwise) since public universities tend to be more restricted than are the private universities in certain of their licensing activ- 
ities. We asked respondents "Are there corporate or legal nuances specific to your TTO (e.g. state laws, charters, federal grant or loan covenants, state or university mandates, etc.) which affect the way in which you try to commercialize university inventions?" More than 47 percent of the public universities indicated that this was true whereas only 30.4 percent of private universities answered yes. To the extent that there are different restrictions on the TTO, this may manifest itself in different objectives of the TTO.

Finally, we consider that the background and experience of personnel in the TTO can influence the importance they attach to objectives. The measure we choose is the number of years of industry experience of the TTO director $\left(I N D E X P_{i}\right)$.

Summary statistics are found in Table 1.

Unfortunately, as will be discussed in the final section, we have limited and incomplete direct measures of the return to the TTO for good performance in obtaining objectives (that is, measures of $\alpha_{S}$ and $\alpha_{R}$ ).

\subsection{Results}

Coefficient estimates and their levels of significance are in Table 2. The coefficients of primary interest are those for $F A C_{i}^{j}$ and $A D M I N_{i}^{j}$, the TTO's perceptions of the importance the faculty and central administration place on objective $j$ as a measure of success. In each regression these coefficients are positive and all are significantly different from zero except for $F A C_{i}^{j}$ in the equation for licenses executed. This lends support for our view that TTOs measure her own success based on her perceptions of both faculty and administration objectives. Moreover, the more important the TTO thinks an objective is to the two principals, the more she pays attention to the objective as a measure of success.

We can further characterize the TTO response to faculty and administration objectives, as well as to the Bayh-Dole charge, by a series of experiments. We begin by calculating the probability that the TTO will report her own measure of valuation as not very important, moderately important or extremely important $\left(T T O_{i}^{j}=1,2,3\right.$, respectively) conditional on the faculty and administration agreeing on the importance of the the objective as a measure of success. That is, we estimate $\operatorname{Pr}\left(T T O_{i}^{j}=k \mid F A C_{i}^{j}=\right.$ $A D M I N_{i}^{j}=l$ ) for $k$ and $l=1,2,3$. This is done for each university and the average estimated probability is reported in the top section of Table 3 . We then assume that the faculty and administration disagree; that is, we estimate $\operatorname{Pr}\left(T T O_{i}^{j}=k \mid F A C_{i}^{j}=l \neq A D M I N_{i}^{j}=m\right)$ for $k=1,2,3$ and $l$ and $m$ equal to 1 or 3 . Results are in the second section of Table 3 . 
Consider first sponsored research. When $F A C_{i}^{j}=A D M I N_{i}^{j}=1$, the TTO is almost certain to agree, however when the $F A C_{i}^{j}=A D M I N_{i}^{j}=2$ or 3 , there is a high probability that the TTO will disagree and value sponsored research lower than does the faculty or central administration. When $F A C_{i}^{j} \neq A D M I N_{i}^{j}$ the TTO will, with low probability, value sponsored research as extremely important, but she will be more influenced by the faculty views than by those of the administration. This supports the result stated in Proposition 2. Many of the TTOs in our sample receive a zero share of sponsored research, yet one third of the licenses executed include sponsored research. In the context of our model, this should occur when the TTO realizes that sponsored research for the inventor improves the probability the invention will be successfully commercialized.

When faculty and administration agree that royalties are either extremely or not very important, there is a very high probability that the TTO will agree. When these groups agree but value royalties only moderately important, there is still a high probability that the TTO will value royalties as extremely important. When the TTO believes the faculty and administration disagree, she is closer to the administration, though there is still a substantial probability that she will agree with the faculty.

In discussions with TTO professionals it is clear that many consider the signing of a license agreement as a compliance measure for the BayhDole Act. This is manifested, we believe, in the estimated probabilities when faculty and administration agree and do not agree on the importance of licenses executed. When there is agreement that licenses executed are not very or moderately important, there is a greater probability that the TTO will value licenses more highly. When the faculty and administration agree that licenses executed are extremely important, the TTO will almost certainly agree. When there is disagreement, there is a very low probability that the TTO will value licenses executed as not very important.

\section{Quality and Stage of Development}

In our survey we asked respondents to indicate the fraction of licensed inventions that were in different stages of development. The majority of inventions were in early stages of development; on average $47 \%$ of licensed inventions were no more than a proof of concept $\left(P R O O F_{i}\right)$ and $37 \%$ have only a prototype available $\left(P T Y P E_{i}\right)$. Of greater interest for our purposes is the variability we observe across universities. For example, 17 of 52 universities report more than $60 \%$ of licensed inventions are in the proof stage 
and 15 report more than $60 \%$ are in the prototype stage. On the other hand 9 report that $10 \%$ or fewer are in the proof stage and 11 report that for the prototype stage. Are these differences merely chance outcomes of research? Is this simply the result of different sciences with different commercial potential and the "black box" probability of success? Our theory suggests that the answer is no. Recall that a necessary condition for an invention to be licensed at stage $\mathrm{j}$ is $p_{j}(0, Q)>\frac{K}{\Pi}$ for $j=C, L$. Faculty quality affects the stage at which an invention can be licensed and therefore the stage at which it might be disclosed. Thus, while comparative static results on quality are ambiguous in general, we expect that if higher quality faculty disclose at all, they will be more likely to disclose at the proof of concept stage than the lab-scale prototype stage. This is surely the case if the marginal effect of an increase in quality is higher at the proof of concept stage than the lab-scale prototype stage.

In this section we propose and estimate an econometric model that relates the stage of development when a license is executed to observable characteristics of universities. We concentrate on the stages of development, $P R O O F_{i}$ and $P T Y P E_{i}$, and relate these to the sources of inventions, the academic quality of the institution, and measures of success of the TTO. Again, as we noted above, we have information on stage of development only for disclosures that are licensed rather than for all disclosures. However, the two should be highly correlated.

To measure the sources of inventions we include the fraction of licenses

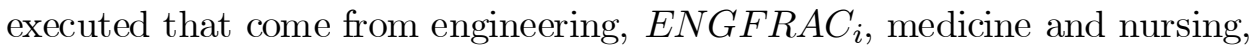
$M E D F R A C_{i}$, and science, SCIFRAC . As a further measure of focus of research at the institution we also include the ratio of industry research support to federal research support, INDFED $D_{i}$. As federal research support tends to be more basic, we expect a smaller ratio to be associated with earlier stage inventions. Our measure of quality of the institution, $Q U A L_{i}$, is the one used above in modeling the importance of different measures of success.

We include several measures of the success of the TTO in executing licenses that generate income. The first is the net royalty income received by the office in the year of our survey (1997), NETINC $C_{i}$. This measure of the "wealth" of the office can influence stage of development by affecting the TTO's marginal utility for another license generating income, and thus less desire to license early. Richer offices, therefore, might discourage disclosures in early stages of development. The second measure of success is the ratio of net income to the number of licenses generating royalties, INCLIC . $_{\text {. }}$ Faculty are expected to be more willing to disclose, which might also affect the timing of disclosure, if they believe the TTO is likely to be successful in 
generating royalty income.

Results are in Table 4. In both equations the coefficient of $Q U A L_{i}$ is significantly different from zero at the $5 \%$ level. Further, higher quality faculty are more likely to disclose in the earliest stage $P R O O F_{i}$ rather than in the later (though still early) stage $P T Y P E_{i}$. In the context of our theory, this supports the view that the marginal impact of quality on the probability of success is highest at the proof of concept stage. Although we did not include quality as an argument in the utility from the inventor's next best alternative or rate of time preference, natural assumptions in this regard would lead one to expect a positive relationship between quality and disclosure at proof of concept stage. ${ }^{11}$

$E N G F R A C_{i}$ and $M E D F R A C_{i}$ are each significant and positive in the $P R O O F_{i}$ equation and significant and negative in the $P T Y P E_{i}$ equation. This would appear to be counterintuitive for $E N G F R A C_{i}$, as engineering tends to be an applied science. One reason for earlier stages of disclosure and license for engineering might be differences in attitudes towards commercialization. If engineering faculty are more willing to be a participant in licensing, then they may well be more willing to disclose early. In addition, as engineering is more applied, it may well be the case that early stage inventions in engineering have, in general, more obvious commercial potential.

$N E T I N C_{i}$ is significant and negative in the $P R O O F_{i}$ equation and insignificant in the PTYPE $E_{i}$ equation. As noted above, we believe this follows from "wealthier" offices discouraging early stage inventions. As predicted $I N C L I C_{i}$ affects stage of invention disclosure and license; more successful offices encourage earlier stages.

\section{Inventor Share}

Finally, recall our model predicts an inverse relation between inventor quality and the shares of license income and sponsored research that the administration will set for the inventor. In our survey we asked for the percentage of royalty income accruing to the TTO and the faculty. Unfortunately, shares of income are not completely revealing of the incentive structure at a university. For example, it is the case that salary increases for both the TTO

\footnotetext{
${ }^{11}$ For example, one would expect higher quality inventors to place more utility on their next best alternative higher and on publishing sooner, which would imply a higher rate of time preference as well. Their disclosure cost also might be higher. Each of these tends to imply earlier disclosure, if it occurs at all.
} 
and the faculty can be influenced by disclosure and licensing success. It is certainly the case that there are additional incentives beyond shares of royalty income for at least the TTO as almost $70 \%$ report that they receive no share of royalty income. In all cases faculty shares, while variable, are greater than zero. We test the above implication of our model using reported faculty shares of royalty income with the caveat that such shares are an imperfect measure of the incentives provided to faculty by the administration. We regress the faculty share on our measure of faculty quality, $Q U A L_{i}$, as well as measures of the sources of inventions, ENGFRAC $M E D F R A C_{i}$, and $S C I F R A C_{i}$ and our measure of the universities focus of research, INDFED . Results are in Table 5. As predicted by our model, faculty shares are negatively related to quality.

\section{Conclusion}

TTOs have primary responsibility for the university licensing function, and, in particular, implementing provisions of the Bayh-Dole Act. These offices are responsible for facilitating faculty disclosure of inventions, evaluating those inventions disclosed, as well as finding licensees and executing contracts on behalf of the central administration for the university (which owns the inventions). Despite their importance, little research has focused on the balancing act played by the TTO and how it affects the nature of inventions disclosed and the outcomes of the process. In this paper, we address this issue directly by modeling the technology transfer process as a game in which the central administration is the principal and both the TTO and faculty are agents, but the TTO is also an agent for the faculty.

Our modeling choice reflects conversations with numerous directors of TTOs. These discussions revealed a major frustration of their job is inducing high quality disclosures (hence the subtitle of our paper). The directors we talked with believe that some of the best inventions may not be disclosed because the most productive faculty are less likely to want to take the time to disclose inventions, much less work on further development. They also believe that many of the inventions disclosed to them are of questionable value. This suggests that the nature of inventions disclosed in U.S. universities is related to faculty quality, but perhaps in unanticipated ways. The analysis also yields predictions for contract terms as well as the stage of development of inventions disclosed. In equilibrium, because of the effect of quality on the probability of success, the TTO may include sponsored research in a license even if she receives a zero share of these funds. Whether the inventor 
discloses, and at what stage, is a function of the equilibrium license income and sponsored research, the inventor's rate of time preference, and quality.

Empirical tests of the theory provide support for the dual agency view that TTOs measure their own success based on their perceptions of both faculty and central administration objectives. Moreover, the more important the TTO thinks an objective is to the two principals, the more she pays attention to the objective as a measure of success. With respect to the stage of development, we find that universities with higher quality faculty have a higher proportion of disclosures licensed in the proof of concept stage, as do universities with higher fractions of inventions from medicine and nursing or from engineering. We also find that universities with greater net income have a smaller proportion of disclosures licensed in the proof of concept stage, although more successful TTOs with greater income per license encourage disclosure at the proof of concept stage. Finally, the share of royalty income allotted to inventors is lower for universities with higher quality faculty.

We think it is worth noting that the theoretical results presented here are also consistent with the empirical results presented in an earlier paper (Thursby et al., 2001), wherein we find a positive relationship between faculty quality and royalty payments and a negative relationship between the frequency of sponsored research agreements in a license and faculty quality.

Although we have found substantial support for our assertion that university TTOs act as an agent for both the administration and the faculty, we acknowledge that there are still many unanswered questions about the process of technology transfer from the academy to industry. For example, the total compensation packages for both inventors and TTO directors include more than just their shares of royalties and sponsored research funds. A more complete modeling of these compensation packages and their choices would be interesting. For example, the inverse relationship between faculty quality and their share of license income is, one supposes, closely linked to the (expected) direct relationship between faculty quality and their salary. Similarly, many universities in our survey noted that faculty had substantial discretion in determining the allocation of the sponsored research funds associated with their licenses. Clearly universities have at their disposal, and frequently employ, a variety of compensation schemes for inventors and TTO directors. Unfortunately, lack of data prevents us from examining the empirical relationship between the "total" compensation packages and the nature of license contracts or the stage of development at which disclosure occurs.

Even in the context of this model, the university administration's prob- 
lem is also quite interesting from another perspective. For a given invention, it is straightforward to solve this problem. One simply determines the smallest shares for the TTO and inventor that induce them to disclose and license this invention at the concept stage (assuming this is feasible), and then the smallest shares that induce them to disclose and license this invention at the prototype stage. The administration then simply compares its expected utility at the concept stage with its discounted expected utility at the prototype stage, and chooses the shares to induce disclosure and licensing at the appropriate stage. However, the solution is less evident when taking into account the fact that shares cannot be chosen for each individual invention, but instead must be chosen for all inventions disclosed over some period of time. The solution to this problem is well beyond the scope of this paper, but is clearly an important topic for future research because it has a substantial impact on the university-industry technology transfer process.

\section{$7 \quad$ References}

Agrawal, A. and R. Henderson, 2002, Putting patents in context, Management Science 48, 44-60.

Atwater, L., Ostroff, C., Yammarino, F.J., and Fleenor, J.W., 1998, Selfother agreement: Does it really matter?' Personnel Psyhology 51, 577-598.

Bercovitz, Janet, Maryann Feldman, Irwin Feller, and Richard Burton, 2001, Organizational structure as a determinant of academic patent and licensing behavior: An exploratory study of Duke, Johns Hopkins, and Pennsylvania State Universities, Journal of Technology Transfer 26, 21-35.

Di Gregoriao, D. and S. Shane, 2000, Why do some universities generate more start-ups than others?," Mimeo, University of Maryland.

Hoppe, Heidrun C., and Emre Ozdenoren, 2001, Intermediation in innovation: The role of technology transfer offices," Mimeo, Universitat Hamburg.

Jensen, R., and M. Thursby, 2001, Proofs and prototypes for sale: The licensing of university inventions," American Economic Review 91, 240-259.

Krosnick, Jon A. and Fabrigar, Leandre R., 1997, Designing rating scales for effective measurement in surveys." in Lyberg, Bieer, Collins, de Leeuw, Dippo, Schwarz, and Trewin, Survey Measurement and Process Quality (New York: Wiley and Sons).

Lach, S. and M. Shankerman, 2002, Incentives and inventive activity in universities," Mimeo, Hebrew University and London School of Economics.

Lewis, K.S., L.M. Jones, M.S. Anderson, D. Blumenthal, and E.G. Camp- 
bell, 2001, Entrepreneurship, secrecy, and productivity: A comparison of clinical and nonclinical faculty, Journal of Technology Transfer 26, 233-245.

Owen-Smith, J. and W.W. Powell, 2001, To patent or not: Faculty decisions and institutional success at technology transfer, Journal of Technology Transfer, 26, 99-114.

Siegel, D., D. Waldman, and A. Link, 1999, Assessing the impact of organizational practices on the productivity of university technology transfer offices: An exploratory study," NBER Working Paper 7256.

Thursby, J., R. Jensen, and M.C. Thursby, 2001, Objectives, characteristics and outcomes of university licensing: A survey of major U.S. universities, Journal of Technology Transfer 26, 59-72.

Thursby, J. and S. Kemp, 2002. Growth and productive efficiency of university intellectual property licensing," Research Policy 31, 109-124.

Thursby, J., and M.C. Thursby, 2002, Who is selling the ivory tower? Sources of growth in university licensing," Management Science 48, 90-104.

\section{Appendix A: Survey Design}

Questionnaires were sent to the top 135 universities in terms of licensing revenue according to the 1996 AUTM Survey, and responses were received from 62 universities. In examining the characteristics of non-respondents compared to respondents, we find that they differ primarily in their volume of licensing activity, with non-respondents being less active than respondents. While this suggests that our sample is not fully representative of the population of universities, it is important to note that the original intent was not to obtain a random sample, but rather to characterize the bulk of licensing activity at U.S. universities. In selecting the 135 universities to sample, we therefore choose the top 135 in terms of licensing activity, and having respondents skewed toward more active offices fits with the original design.

For more detail on survey design see Jensen and Thursby (2001) and Thursby et al. (2002). For the survey questions relevant for this paper there are two important, potential problems. First, TTOs do not maintain files on the fraction of inventions in different stages of development. As such, in answering our question about stage of development answers are based on the respondents perceptions, thus it is expected that there is a lot of noise in the data. However, there is no reason to suspect that answers are biased given that our stage of development terminology is standard across TTOs. Second, our objectives questions are based on a semantic scale and respon- 
dents may perceive the same environment but use the scale differently. To minimize error of this type, we based our scale on research results from the literature on optimal rating scales. As discussed by Krosnick and Fabrigar (1997), research on the reliability of rating scales suggests people can distinguish among and have consistent interpretations of the four point scale, "extremely important," "moderately important," "not very important," and "not applicable."

\section{Appendix B}

\subsection{Proof of Theorem 1}

If $p_{j}(0, Q)>\frac{K}{\Pi}$, then $E \Pi_{j}(0,0)>0$. Because

$$
\frac{\partial E U_{T j}}{\partial R}=p_{j} \frac{\partial U_{T}\left(\alpha_{R} R, \alpha_{S} S, 1\right)}{\partial y_{T}} \alpha_{R}>0
$$

and

$$
\begin{aligned}
\frac{\partial E U_{T j}}{\partial S}= & \frac{\partial p_{j}}{\partial S}\left[U_{T}\left(\alpha_{R} R, \alpha_{S} S, 1\right)-U_{T}\left(0, \alpha_{S} S, 1\right)\right]+ \\
& {\left[p_{j} \frac{\partial U_{T}\left(\alpha_{R} R, \alpha_{S} S, 1\right)}{\partial f_{T}}+\left(1-p_{j}\right) \frac{\partial U_{T}\left(0, \alpha_{S} S, 1\right)}{\partial f_{T}}\right] \alpha_{S}>0 }
\end{aligned}
$$

for all $R \geq 0$ and $S \geq 0$, it follows that the solution to (5) must have the licensee's participation constraint binding $E \Pi_{j}\left(R_{j}^{*}, S_{j}^{*}\right)=0$, and either $R_{j}^{*}>0, S_{j}^{*}>0$, or both. The condition $E \Pi_{j}(R, S)=0$ implicitly defines $R$ as a function of $S$, say $R=\phi_{j}(S)$, where $\phi_{j}^{\prime}(S)=-\frac{\frac{\partial E \Pi_{i}}{\partial S}}{\frac{\partial E \Pi_{i}}{\partial R}}$ and $R_{j}^{*}=\phi_{j}\left(S_{j}^{*}\right)$. Note that, because

$$
\frac{\partial E \Pi_{j}\left(R_{j}^{*}, S_{j}^{*}\right)}{\partial R}=-p_{j}<0
$$

but

$$
\frac{\partial E \Pi_{j}\left(R_{j}^{*}, S_{j}^{*}\right)}{\partial S}=\frac{\partial p_{j}}{\partial S}\left(\Pi-R_{j}^{*}\right)-1
$$

is ambiguous in general, $\phi_{j}^{\prime}(S)$ has the sign of $-\frac{\partial E \Pi_{j}\left(R_{i}^{*}, S_{i}^{*}\right)}{\partial S}$.

Let $F_{j}(R, S, \lambda)=E U_{T j}(R, S)+\lambda E \Pi_{j}(R, S)$ where $\lambda$ is a Lagrange multiplier. If an interior solution with $R_{j}^{*}>0$ and $S_{j}^{*}>0$ exists, then the first order necessary conditions are

$$
\frac{\partial F_{j}\left(R_{j}^{*}, S_{j}^{*}\right)}{\partial R}=\frac{\partial E U_{T j}\left(R_{j}^{*}, S_{j}^{*}\right)}{\partial R}+\lambda_{j}^{*} \frac{\partial E \Pi_{j}\left(R_{j}^{*}, S_{j}^{*}\right)}{\partial R}=0,
$$




$$
\frac{\partial F_{j}\left(R_{j}^{*}, S_{j}^{*}\right)}{\partial S}=\frac{\partial E U_{T j}\left(R_{j}^{*}, S_{j}^{*}\right)}{\partial S}+\lambda_{j}^{*} \frac{\partial E \Pi_{j}\left(R_{j}^{*}, S_{j}^{*}\right)}{\partial S}=0
$$

and

$$
\frac{\partial F_{j}\left(R_{j}^{*}, S_{j}^{*}\right)}{\partial \lambda}=E \Pi_{j}\left(R_{j}^{*}, S_{j}^{*}\right)=0 .
$$

Hence, $\lambda^{*}=-\frac{\frac{\partial E U_{T j}\left(R_{i}^{*}, S_{i}^{*}\right)}{\partial R}}{\frac{\partial E \Pi_{T j}\left(R_{i}^{*}, S_{i}^{*}\right)}{\partial R}}>0$, whence $\frac{\partial E \Pi_{j}\left(R_{j}^{*}, S_{i}^{*}\right)}{\partial S}=\frac{\partial p_{i}}{\partial S}\left(\Pi-R_{j}^{*}\right)-1<0$ and $\phi_{j}^{\prime}\left(S_{j}^{*}\right)<0$.

Using the standard Kuhn-Tucker approach, the first order necessary conditions for a maximum at $\left(R_{j}^{0}, 0\right)$ are

$$
\begin{aligned}
& \frac{\partial F_{j}\left(R_{j}^{0}, 0\right)}{\partial R}=\frac{\partial E U_{T j}\left(R_{j}^{0}, 0\right)}{\partial R}+\lambda^{R} \frac{\partial E \Pi_{T j}\left(R_{j}^{0}, 0\right)}{\partial R}=0, \\
& \frac{\partial F_{j}\left(R_{j}^{0}, 0\right)}{\partial S}=\frac{\partial E U_{T j}\left(R_{j}^{0}, 0\right)}{\partial S}+\lambda^{R} \frac{\partial E \Pi_{T j}\left(R_{j}^{0}, 0\right)}{\partial S} \leq 0,
\end{aligned}
$$

and

$$
\frac{\partial F_{j}\left(R_{j}^{0}, 0\right)}{\partial \lambda}=E \Pi_{T j}\left(R_{j}^{0}, 0\right)=0
$$

where the last condition implies $R_{j}^{0}$ is defined by $p_{j}(0, Q)\left(\Pi-R_{j}^{0}\right)=K$, and the first condition implies $\lambda^{R}=-\frac{\frac{\partial E U_{T j}\left(R_{i}^{0}, 0\right)}{\partial R}}{\frac{\partial E \Pi_{T j}\left(R_{1}^{0}, 0\right)}{\partial R}}>0$ because $\frac{\partial E U_{T i}}{\partial R}>0$ and $\frac{\partial E \Pi_{i}}{\partial R}<0$. Therefore, because $\frac{\partial E U_{T j}\left(R_{i}^{0}, 0\right)}{\partial S}>0$, the second condition cannot hold unless $\frac{\partial E \Pi_{T j}\left(R_{i}^{0}, 0\right)}{\partial S}<0$, whence $\phi_{j}^{\prime}(0)<0$.

Similarly, the standard Kuhn-Tucker necessary conditions for a maximum at $\left(0, S_{j}^{0}\right)$ are

$$
\begin{aligned}
& \frac{\partial F_{j}\left(0, S_{j}^{0}\right)}{\partial R}=\frac{\partial E U_{T j}\left(0, S_{j}^{0}\right)}{\partial R}+\lambda^{S} \frac{\partial E \Pi_{T j}\left(0, S_{j}^{0}\right)}{\partial R} \leq 0, \\
& \frac{\partial F_{j}\left(0, S_{j}^{0}\right)}{\partial S}=\frac{\partial E U_{T j}\left(0, S_{j}^{0}\right)}{\partial S}+\lambda^{S} \frac{\partial E \Pi_{T j}\left(0, S_{j}^{0}\right)}{\partial S}=0,
\end{aligned}
$$

and

$$
\frac{\partial F_{j}\left(0, S_{j}^{0}\right)}{\partial \lambda}=E \Pi_{T j}\left(0, S_{j}^{0}\right)=0,
$$

where the last condition implies $S_{j}^{0}$ is defined by $p_{j}\left(S_{j}^{0}, Q\right) \Pi=K$, and the first condition implies $\lambda^{S}=-\frac{\frac{\partial E U_{T j}\left(0, S_{j}^{0}\right)}{\partial R}}{\frac{\partial E \Pi_{T j}\left(0, S_{j}^{0}\right)}{\partial R}} \geq 0$ because $\frac{\partial E U_{T i}}{\partial R}>0$ and 
$\frac{\partial E \Pi_{j}}{\partial R}<0$. Therefore, because $\frac{\partial E U_{T j}\left(0, S_{j}^{0}\right)}{\partial S}>0$, the second condition cannot hold unless $\frac{\partial E \Pi_{T j}\left(0, S_{i}^{0}\right)}{\partial S}<0$, whence $\phi_{j}^{\prime}\left(S_{j}^{0}\right)<0$.

The second order sufficient condition for a maximum is negative definiteness of the bordered Hessian matrix $H_{j}$ for all $R \geq 0$ and $S \geq 0$, or $\operatorname{det} H_{j}>$ 0, which we assume. Assuming an interior solution, $R_{j}^{*}>0$ and $S_{j}^{*}>0$, standard comparative statics analysis implies that, for $x=Q, \Pi, \alpha_{R}, \alpha_{S}$,

$$
\frac{\partial R_{j}^{*}}{\partial x}=\frac{\operatorname{det} H_{j}(R, x)}{\operatorname{det} H_{j}}
$$

and

$$
\frac{\partial S_{j}^{*}}{\partial x}=\frac{\operatorname{det} H_{j}(S, x)}{\operatorname{det} H_{j}}
$$

where det $H_{j}(R, x)=\frac{\partial^{2} F_{i}}{\partial \lambda \partial S}\left[\frac{\partial^{2} F_{i}}{\partial R \partial x} \frac{\partial^{2} F_{i}}{\partial S \partial \lambda}-\frac{\partial^{2} F_{i}}{\partial R \partial \lambda} \frac{\partial^{2} F_{i}}{\partial S \partial x}\right]+\frac{\partial^{2} F_{i}}{\partial \lambda \partial x}\left[\frac{\partial^{2} F_{i}}{\partial R \partial \lambda} \frac{\partial^{2} F_{i}}{\partial S^{2}}-\frac{\partial^{2} F_{i}}{\partial R \partial S} \frac{\partial^{2} F_{i}}{\partial S \partial \lambda}\right]$ and $\operatorname{det} H_{j}(S, x)=\frac{\partial^{2} F_{i}}{\partial \lambda \partial R}\left[\frac{\partial^{2} F_{i}}{\partial S \partial x} \frac{\partial^{2} F_{i}}{\partial R \partial \lambda}-\frac{\partial^{2} F_{i}}{\partial S \partial \lambda} \frac{\partial^{2} F_{i}}{\partial R \partial x}\right]+\frac{\partial^{2} F_{i}}{\partial \lambda \partial x}\left[\frac{\partial^{2} F_{i}}{\partial R^{2}} \frac{\partial^{2} F_{i}}{\partial S \partial \lambda}-\frac{\partial^{2} F_{i}}{\partial R \partial \lambda} \frac{\partial^{2} F_{i}}{\partial R \partial S}\right]$.

First consider the sponsored research share. Notice $\frac{\partial^{2} F_{j}}{\partial R \partial \alpha_{S}}=p_{j} \frac{\partial^{2} U_{T}\left(\alpha_{R} R, \alpha_{S} S, 1\right)}{\partial y_{T} \partial f_{T}} \alpha_{R} S$ and $\frac{\partial^{2} F_{j}}{\partial S \partial \alpha_{S}}=\frac{\partial p_{i}}{\partial S}\left[\frac{\partial U_{T}\left(\alpha_{R} R, \alpha_{S} S, 1\right)}{\partial f_{T}}-\frac{\partial U_{T}\left(0, \alpha_{S} S, 1\right)}{\partial f_{T}}\right] S+\left[p_{j} \frac{\partial^{2} U_{T}\left(\alpha_{R} R, \alpha_{S} S, 1\right)}{\partial f_{T}^{2}}+(1-\right.$ $\left.\left.p_{j}\right) \frac{\partial^{2} U_{T}\left(0, \alpha_{S} S, 1\right)}{\partial f_{T}^{2}}\right] \alpha_{S} S$ are both ambiguous, and $\frac{\partial^{2} F_{j}}{\partial \lambda \partial \alpha_{S}}=0$. Because $\frac{\partial^{2} F_{j}}{\partial \lambda \partial S}=$ $\frac{\partial E \Pi_{i}}{\partial S}<0$ and $\frac{\partial^{2} F_{i}}{\partial \lambda \partial R}=\frac{\partial E \Pi_{i}}{\partial R}<0, \operatorname{det} H_{j}\left(R, \alpha_{S}\right)=\frac{\partial^{2} F_{i}}{\partial \lambda \partial S}\left[\frac{\partial^{2} F_{i}}{\partial R \partial \alpha_{S}} \frac{\partial^{2} F_{i}}{\partial S \partial \lambda}-\right.$ $\left.\frac{\partial^{2} F_{i}}{\partial R \partial \lambda} \frac{\partial^{2} F_{i}}{\partial S \partial \alpha_{S}}\right]>0$ and $\operatorname{det} H_{j}\left(S, \alpha_{S}\right)=\frac{\partial^{2} F_{i}}{\partial \lambda \partial R}\left[\frac{\partial^{2} F_{i}}{\partial S \partial \alpha_{S}} \frac{\partial^{2} F_{i}}{\partial R \partial \lambda}-\frac{\partial^{2} F_{i}}{\partial S \partial \lambda} \frac{\partial^{2} F_{i}}{\partial R \partial \alpha_{S}}\right]<0$ if $\frac{\partial^{2} F_{j}}{\partial R \partial \alpha_{S}} \geq 0$ and $\frac{\partial^{2} F_{i}}{\partial S \partial \alpha_{S}} \leq 0$. In general, these conditions need not hold, but they do for certain classes of utility functions. For example, they hold if TTO utility is additively separable, in which case $\frac{\partial R_{i}^{*}}{\partial \alpha_{S}}>0>\frac{\partial S_{i}^{*}}{\partial \alpha_{S}}$ because $\operatorname{det} H_{j}>0$ by second order conditions.

Next consider the license revenue share. Note that $\frac{\partial^{2} F_{j}}{\partial S \partial \alpha_{R}}=\frac{\partial p_{i}}{\partial S} \frac{\partial U_{T}\left(\alpha_{R} R, \alpha_{S} S, 1\right)}{\partial y_{T}} R+$ $p_{j} \frac{\partial^{2} U_{T}\left(\alpha_{R} R, \alpha_{S} S, 1\right)}{\partial f_{T} \partial y_{T}} \alpha_{S} R$ is ambiguous, while $\frac{\partial^{2} F_{j}}{\partial R \partial \alpha_{R}}=p_{j} \frac{\partial^{2} U_{T}\left(\alpha_{R} R, \alpha_{S} S, 1\right)}{\partial y_{T}^{2}} \alpha_{R} R$ $<0$ and $\frac{\partial^{2} F_{j}}{\partial \lambda \partial \alpha_{R}}=0$. Now $\operatorname{det} H_{j}\left(R, \alpha_{R}\right)=\frac{\partial^{2} F_{i}}{\partial \lambda \partial S}\left[\frac{\partial^{2} F_{j}}{\partial R \partial \alpha R} \frac{\partial^{2} F_{i}}{\partial S \partial \lambda}-\frac{\partial^{2} F_{i}}{\partial R \partial \lambda} \frac{\partial^{2} F_{j}}{\partial S \partial \alpha_{R}}\right]$ and $\operatorname{det} H_{j}\left(S, \alpha_{R}\right)=\frac{\partial^{2} F_{i}}{\partial \lambda \partial R}\left[\frac{\partial^{2} F_{j}}{\partial S \partial \alpha_{R}} \frac{\partial^{2} F_{i}}{\partial R \partial \lambda}-\frac{\partial^{2} F_{j}}{\partial S \partial \lambda} \frac{\partial^{2} F_{i}}{\partial R \partial \alpha_{R}}\right]$ are ambiguous, in general, and so are $\frac{\partial R_{j}^{*}}{\partial \alpha_{R}}$ and $\frac{\partial S_{j}^{*}}{\partial \alpha_{R}}$. However, $\operatorname{det} H_{j}\left(R, \alpha_{R}\right)<0$ and $\operatorname{det} H_{j}\left(S, \alpha_{R}\right)>$ 0 whenever TTO utility is additively separable, in which case $\frac{\partial S_{j}^{*}}{\partial \alpha_{R}}>0>$ $\frac{\partial R_{j}^{*}}{\partial \alpha_{R}}$.

Third, consider faculty quality. Note that $\frac{\partial^{2} F_{i}}{\partial R \partial Q}=\frac{\partial p_{i}}{\partial Q} \frac{\partial U_{T}\left(\alpha_{R} R, \alpha_{S} S, 1\right)}{\partial y_{T}} \alpha_{R}-$ $\lambda \frac{\partial p_{i}}{\partial Q}$ and $\frac{\partial^{2} F_{i}}{\partial S \partial Q}=\frac{\partial^{2} p_{i}}{\partial S \partial Q}\left[U_{T}\left(\alpha_{R} R, \alpha_{S} S, 1\right)-U_{T}\left(0, \alpha_{S} S, 1\right)\right]+\frac{\partial p_{i}}{\partial Q}\left[\frac{\partial U_{T}\left(\alpha_{R} R, \alpha_{S} S, 1\right)}{\partial f_{T}}-\right.$ 
$\left.\frac{\partial U_{T}\left(0, \alpha_{S} S, 1\right)}{\partial f_{T}}\right] \alpha_{S}+\lambda \frac{\partial^{2} p_{i}}{\partial S \partial Q}(\Pi-R)$ are both ambiguous, though $\frac{\partial^{2} F_{i}}{\partial \lambda \partial Q}=\frac{\partial p_{i}}{\partial Q}(\Pi-R)>$ 0 Thus, $\frac{\partial R_{i}^{*}}{\partial Q}$ and $\frac{\partial S_{i}^{*}}{\partial Q}$ are ambiguous, in general.

Fourth, consider the profit from a success. Note that $\frac{\partial^{2} F_{i}}{\partial R \partial \Pi}=0, \frac{\partial^{2} F_{i}}{\partial S \partial \Pi}=$ $\lambda \frac{\partial p_{i}}{\partial S}>0$, and $\frac{\partial^{2} F_{i}}{\partial \lambda \partial \Pi}=p_{j}>0$. Thus, again $\operatorname{det} H_{j}(R, \Pi)=\frac{\partial^{2} F_{i}}{\partial \lambda \partial S}\left[\frac{\partial^{2} F_{i}}{\partial R \partial \Pi} \frac{\partial^{2} F_{i}}{\partial S \partial \lambda}-\right.$ $\left.\frac{\partial^{2} F_{i}}{\partial R \partial \lambda} \frac{\partial^{2} F_{i}}{\partial S \partial \Pi}\right]+\frac{\partial^{2} F_{i}}{\partial \lambda \partial \Pi}\left[\frac{\partial^{2} F_{i}}{\partial R \partial \lambda} \frac{\partial^{2} F_{i}}{\partial S^{2}}-\frac{\partial^{2} F_{i}}{\partial R \partial S} \frac{\partial^{2} F_{i}}{\partial S \partial \lambda}\right]$ and $\operatorname{det} H_{j}(S, \Pi)=\frac{\partial^{2} F_{i}}{\partial \lambda \partial R}\left[\frac{\partial^{2} F_{i}}{\partial S \partial \Pi} \frac{\partial^{2} F_{i}}{\partial R \partial \lambda}-\right.$ $\left.\frac{\partial^{2} F_{i}}{\partial S \partial \lambda} \frac{\partial^{2} F_{i}}{\partial R \partial \Pi}\right]+\frac{\partial^{2} F_{i}}{\partial \lambda \partial \Pi}\left[\frac{\partial^{2} F_{i}}{\partial R^{2}} \frac{\partial^{2} F_{i}}{\partial S \partial \lambda}-\frac{\partial^{2} F_{i}}{\partial R \partial \lambda} \frac{\partial^{2} F_{i}}{\partial R \partial S}\right]$ are ambiguous, in general.

Finally, consider the cost of commercialization. Note that $\frac{\partial^{2} F_{j}}{\partial R \partial K}=$ $\frac{\partial^{2} F_{i}}{\partial S \partial K}=0$ and $\frac{\partial^{2} F_{i}}{\partial \lambda \partial K}=-1>0$. Thus, again $\operatorname{det} H_{j}(R, K)=-\left[\frac{\partial^{2} F_{i}}{\partial R \partial S} \frac{\partial^{2} F_{i}}{\partial S \partial \lambda}-\right.$ $\left.\frac{\partial^{2} F_{i}}{\partial R \partial \lambda} \frac{\partial^{2} F_{i}}{\partial S^{2}}\right]$ and $\operatorname{det} H_{j}(S, K)=-\left[\frac{\partial^{2} F_{i}}{\partial R^{2}} \frac{\partial^{2} F_{i}}{\partial S \partial \lambda}-\frac{\partial^{2} F_{i}}{\partial R \partial \lambda} \frac{\partial^{2} F_{i}}{\partial R \partial S}\right]$ are ambiguous, in general. However, if $\frac{\partial^{2} F_{j}}{\partial R \partial S} \geq 0$, then $\operatorname{det} H_{j}(R, K)>0>\operatorname{det} H_{j}(S, K)$, so $\frac{\partial R_{i}^{*}}{\partial K}>0>\frac{\partial S_{i}^{*}}{\partial K}$.

However, recall that the firm's participation constraint must bind and that $\frac{\partial E \Pi_{j}\left(R_{j}^{*}, S_{j}^{*}\right)}{\partial R}<0$ and $\frac{\partial E \Pi_{j}\left(R_{j}^{*}, S_{j}^{*}\right)}{\partial S}<0$ at the maximum. Hence, any parametric change that increases $E \Pi_{j}(R, S)$ in general implies that now $E \Pi_{j}\left(R_{j}^{*}, S_{j}^{*}\right)>0$. Therefore, either $R_{j}^{*}$, or $S_{j}^{*}$, or both, must increase to restore equality in the constraint. That is, if $\frac{\partial E \Pi_{j}(R, S)}{\partial x}>0$, then either $\frac{\partial R_{i}^{*}}{\partial x}>0, \frac{\partial S_{i}^{*}}{\partial x}>0$, or both. Graphically, the constraint $E \Pi_{j}(R, S)=0$ implicitly defines $R$ as a function of $S$, say $R=\phi_{j}(S)$, where $\phi_{j}^{\prime}(S)=$ $-\frac{\frac{\partial E \Pi_{i}}{\partial S}}{\frac{\partial E \Pi_{i}}{\partial R}}<0$ because $E \Pi_{j}(R, S)$ is assumed to be decreasing in $R$ and $S$ at the maximum. Thus, any parametric change that increases $E \Pi_{j}(R, S)$ results in an outward shift of the constraint from the point $\left(R_{j}^{*}, S_{j}^{*}\right)$, so either $R_{j}^{*}$,or $S_{j}^{*}$, or both, must increase at the new maximum on the new constraint. The statement of the theorem then follows from the fact that $\frac{\partial E \Pi_{j}\left(R_{i}^{*}, S_{i}^{*}\right)}{\partial Q}=\frac{\partial p_{j}\left(S_{i}^{*}, Q\right)}{\partial Q}\left(\Pi-R_{j}^{*}\right)>0, \frac{\partial E \Pi_{j}\left(R_{i}^{*}, S_{j}^{*}\right)}{\partial \Pi}=p_{j}\left(S_{j}^{*}, Q\right)>0$, and $\frac{\partial E \Pi_{j}\left(R_{j}^{*}, S_{j}^{*}\right)}{\partial K}=-1<0$.

\subsection{Proof of Theorem 2}

As noted in the proof of Theorem 1, the first order necessary conditions for a maximum at $\left(R_{j}^{0}, 0\right)$ are $\frac{\partial F_{j}\left(R_{j}^{0}, 0\right)}{\partial R}=\frac{\partial E U_{T j}\left(R_{j}^{0}, 0\right)}{\partial R}+\lambda^{R} \frac{\partial E \Pi_{T j}\left(R_{j}^{0}, 0\right)}{\partial R}=0$, $\frac{\partial F_{j}\left(R_{j}^{0}, 0\right)}{\partial S}=\frac{\partial E U_{T j}\left(R_{i}^{0}, 0\right)}{\partial S}+\lambda^{R} \frac{\partial E \Pi_{T j}\left(R_{i}^{0}, 0\right)}{\partial S} \leq 0$, and $\frac{\partial F_{j}\left(R_{j}^{0}, 0\right)}{\partial \lambda}=E \Pi_{T j}\left(R_{j}^{0}, 0\right)=$ 0 , where the first implies $\lambda_{j}^{0}=-\frac{\frac{\partial E U_{T j}\left(R_{j}^{0}, 0\right)}{\partial R}}{\frac{\partial E \Pi_{T j}\left(R_{j}^{0}, 0\right)}{\partial R}}>0$. Because $\frac{\partial E U_{T j}(R, S)}{\partial S}>0$ 
in general, and $\frac{\partial E \Pi_{j}\left(R_{j}^{0}, 0\right)}{\partial S}=\frac{\partial p_{j}(0, Q)}{\partial S}\left(\Pi-R_{j}^{0}\right)-1$, we have $\frac{\partial E U_{T j}(R, S)}{\partial S}>0$ if $\frac{\partial p_{j}(0, Q)}{\partial S}>\frac{1}{\Pi-R_{j}^{0}}$. In this case the corner solution $\left(R_{j}^{0}, 0\right)$ on the zero expected profit constraint cannot be a maximum, which with $p_{j}(0, Q)>\frac{K}{\Pi}$ implies the optimal contract must have $S_{j}^{*}>0$. 


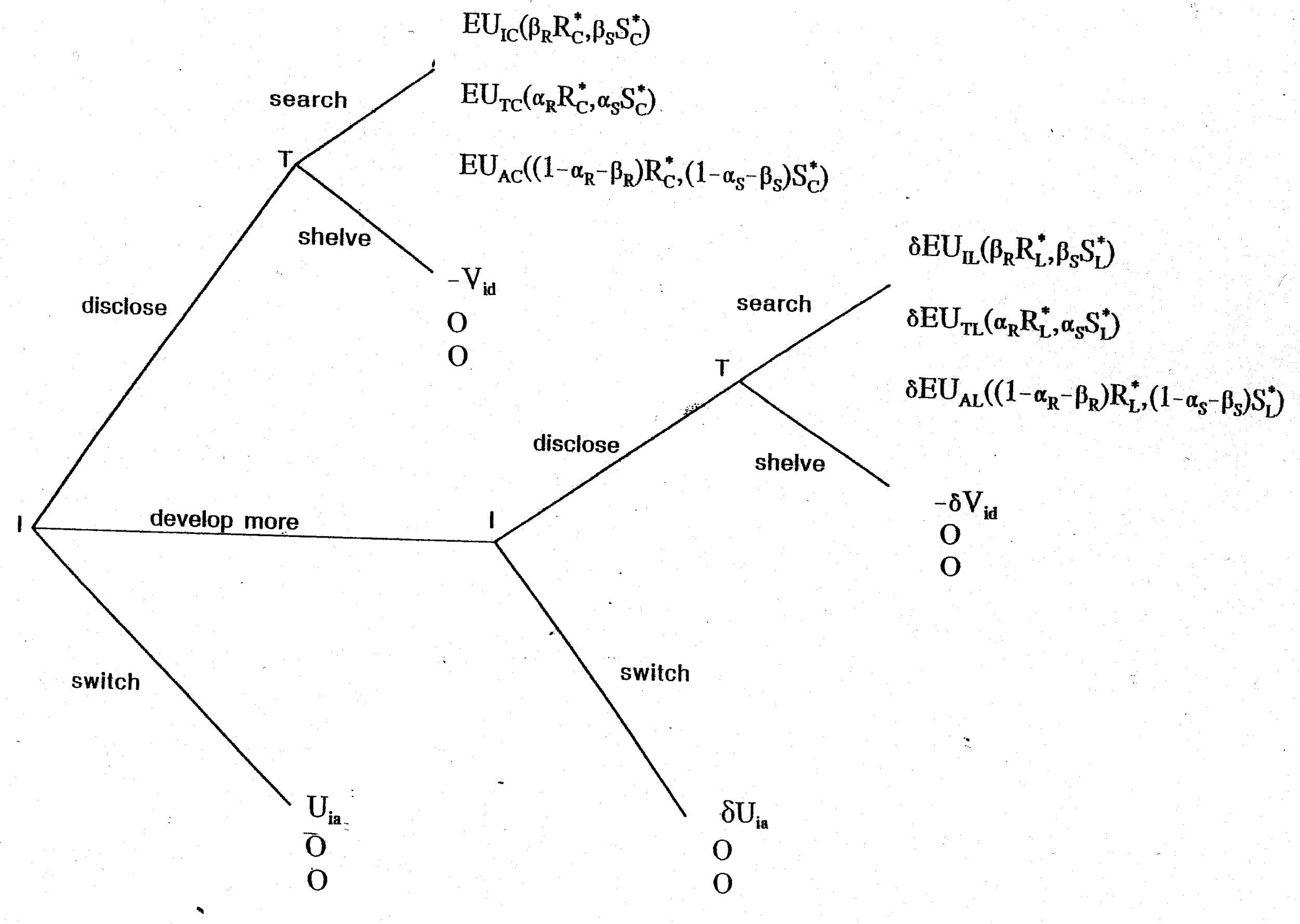

Figure 1 
Table 1. Summary Statistics

\section{Variable}

Fraction public universities

Faculty quality

Faculty income shares

Fraction proof of concept

Fraction prototype available

Industry to federal expenditures

Industrial experience

Income per license (millions of dollars)

Net income (millions of dollars)

Fraction of licenses from School of Science

Fraction of licenses from School of Engineering

Fraction of licenses from Medical Schools
Fraction with medical school

\# Obs. Mean Std. Dev.

$\begin{array}{lccc}\text { PUBLIC } & 62 & 0.63 & \\ \text { MEDSCHUL } & 62 & 0.60 & \\ \text { QUAL } & 60 & 3.14 & 0.83 \\ & 62 & 38.51 & 12.69 \\ \text { PROOF } & 52 & 44.16 & 28.14 \\ \text { PTYPE } & 52 & 37.19 & 27.66 \\ \text { INDEXP } & 54 & 11.22 & 9.68 \\ \text { INDFED } & 61 & 0.14 & 0.09 \\ \text { INCLIC } & 57 & 0.10 & 0.19 \\ \text { NETINC } & 61 & 4.21 & 8.57 \\ \text { SCIFRAC } & 58 & 21.90 & 18.37 \\ \text { ENGFRAC } & 58 & 28.69 & 22.82 \\ \text { MEDFRAC } & 58 & 33.08 & 33.69\end{array}$

TTO importance

$\begin{array}{rlll}\text { Royalties } & 61 & 2.69 & 0.50 \\ \text { Sponsored research } & 61 & 2.38 & 0.55 \\ \text { Licenses executed } & 62 & 2.66 & 0.54\end{array}$

Faculty importance

Royalties

Sponsored research

Licenses executed

Administration importance

Royalties

Sponsored research

Licenses executed $\begin{array}{lll}61 & 2.18 & 0.70\end{array}$

$\begin{array}{lll}61 & 2.72 & 0.52\end{array}$

$\begin{array}{lll}61 & 2.31 & 0.76\end{array}$

$\begin{array}{lll}61 & 2.43 & 0.62\end{array}$

$\begin{array}{lll}57 & 1.75 & 0.66\end{array}$

$\begin{array}{lll}61 & 2.03 & 0.68\end{array}$ 
Table 2. Ordered Probit Results on TTO Measures of Success

SPONSORED

RESEARCH

FAC -- Spon.Research

ADMIN -- Spon. Research

FAC -- Royalties

ADMIN -- Royalties

FAC -- Licenses

ADMIN -- Licenses

PROOF

PTYPE

MEDSCHL

QUAL

INDFED

PUBLIC

INDEXP

Psuedo R-Square

Number of observations

Chi-square statistic for overall fit
$1.650^{* * *}$

$0.957^{* * *}$

$\begin{array}{lcc} & 3.899^{* *} & \\ & 7.002^{* *} & \\ & & 0.538 \\ & & 1.158^{* * *} \\ -0.027^{* * *} & -0.198^{* *} & 0.005 \\ -0.023^{* *} & -0.081^{*} & 0.008 \\ -0.003 & 5.468^{* *} & -0.155 \\ 0.068 & 2.579^{*} & 0.606^{*} \\ -0.766 & 76.499^{*} & -1.666 \\ 0.151 & -0.311^{*} & 0.668 \\ -0.008 & 0.014 & -0.016 \\ 0.313 & 0.726^{*} & 0.257 \\ 42 & 42^{* *} & 38 \\ 27.26^{* *} & 17.88^{* *} & 19.92^{* *}\end{array}$

*** Significant at $1 \%$ level

** Significant at $5 \%$ level

* Significant at $10 \%$ level

+ Bivariate probit model as explained in text.

LICENSES

ROYALTIES + EXECUTED 


\section{Table 3. Estimated Conditional Probabilities}

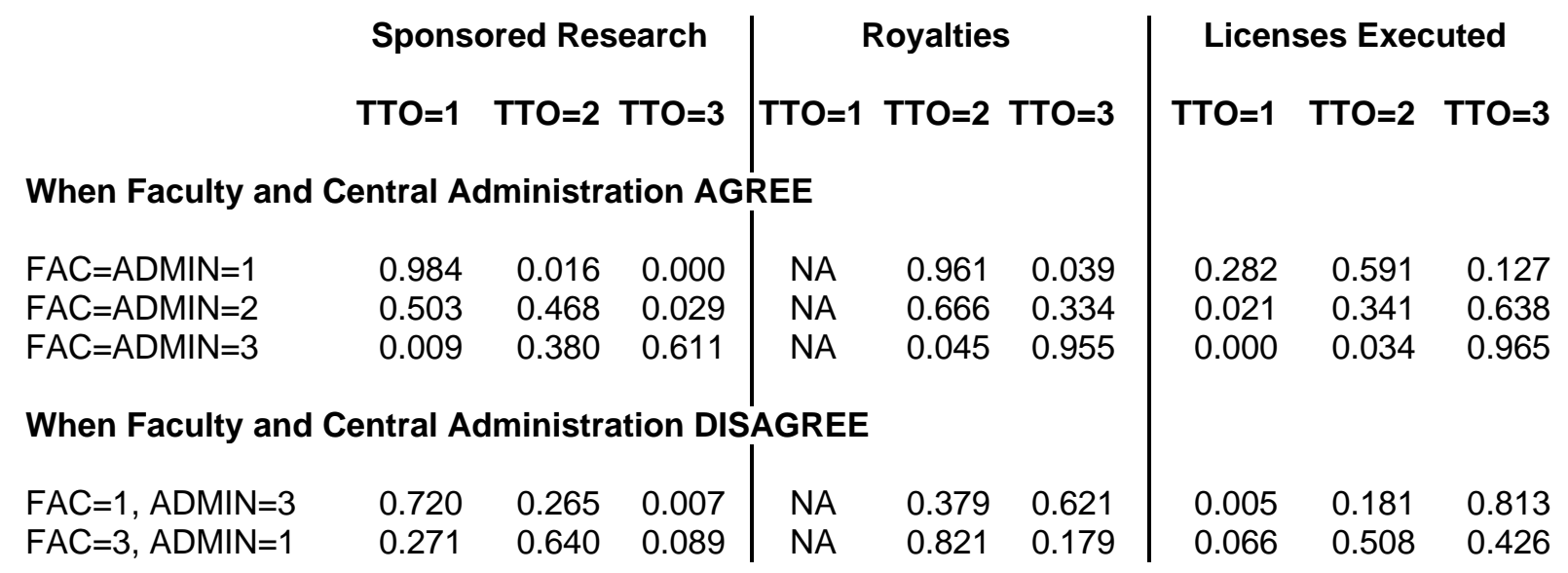

NA: Bivariate probit model is used. 


\section{Table 4. Regression Results for Stage of Development}

Proof

ENGFRAC

SCIFRAC

MEDFRAC

QUAL

INDFED

INCLIC

NETINC

CONSTANT

R-Square

Number of observations

F-statistic for overall fit

*** Significant at $1 \%$ level

** Significant at $5 \%$ level

* Significant at $10 \%$ level
Prototype

$\begin{array}{rc}0.469 * * & -0.440 * \\ -0.171 & -0.061 \\ 0.305 * & -0.490 * * \\ 12.651 * * & -9.006 \text { * } \\ 16.478 & -68.974 \\ 36.788 * & -49.898 \text { ** } \\ -0.594 * * & -0.184 \\ -20.903 & 113.708 \text { *** } \\ 0.211 & 0.273 \\ 47 & 46 \\ 3.04 \text { ** } & 3.49 \text { * }\end{array}$




\section{Table 5. Faculty Shares}

ENGFRAC

SCIFRAC

MEDFRAC

QUAL

INDFED

CONSTANT

R-Square

Number of observations

$F$ statistic for overall fit

*** Significant at $1 \%$ level

** Significant at 5\% level

* Significant at $10 \%$ level
-0.173 *

-0.201 **

$-0.048$

-3.262 **

$-8.463$

$60.295^{* * *}$

0.226

55

$4.83^{* * *}$ 